\title{
PHYTOCHEMICAL ANALYSIS, ANTIOXIDANT, ANTIMICROBIAL ACTIVITIES AND GC-MS PROFILING OF DRYMARIA DIANDRA BLUME
}

\author{
Saroj Kafle*, Ram Chandra Basnyat" and Meena Rajbhandari** \\ ${ }^{*}$ Central Department of Chemistry, Tribhuvan University, Kathmandu. \\ ${ }^{* *}$ Research Center for Applied Science and Technology, Tribhuvan University, Kathmandu.
}

\begin{abstract}
Drymaria diandra is used in Nepalese traditional medicine to treat various ailments. The hexane, dichloromethane, ethyl acetate, methanol and 50\% aqueous methanol extracts of $D$. diandra were prepared and screened for the presence of different classes of phytochemicals. Methanol and 50\% aqueous methanol extracts showed the presence of phenolics, flavonoids and carbohydrates so their total contents were estimated. The highest amount of phenolics and flavonoids were found in methanol extract (190.58 $\pm 2.21 \mathrm{mg} \mathrm{GAE} / \mathrm{g}$ extract and $69.25 \pm 7.91 \mathrm{mg} \mathrm{CE} / \mathrm{g}$ extract respectively). The highest amount of sugar was found in $50 \%$ methanol extract (185.60 $2.53 \mathrm{mg} \mathrm{GE} / \mathrm{g}$ extract). Similarly, the extracts were tested for the antibacterial activity against one gram negative bacteria, Escherichia coli and one gram positive bacteria Staphylococcus aureus. All the tested extracts showed good antibacterial activity against both bacteria with the inhibition zone ranging from $10-22 \mathrm{~mm}$. The free radical scavenging activity was determined using DPPH free radical. Both methanol and 50\% aqueous methanol extracts showed strong antioxidant activity $\left(\mathrm{IC}_{50} 13.61\right.$ and $16.94 \mu \mathrm{g} / \mathrm{ml}$ respectively). The GC-MS analysis of hexane extract revealed the presence of more than 22 compounds. However, 9 compounds were identified by comparing the mass fragmentation pattern of each compound with the standard NIST mass spectral database.
\end{abstract}

Keywords: Antioxidant; Antimicrobial; GC-MS; Phytochemical.

\section{INTRODUCTION}

Medicinal plants are still a significant source of drugs and leads. They play a vital role in preventing, healing and curing of human diseases because of the presence of different classes of phytochemicals ${ }^{1}$. The search for new pharmacologically active agents obtained by screening plant extracts has led to the discovery of many clinically useful drugs that play a major role in the treatment of human diseases ${ }^{2}$.

The search for antibacterial from medicinal plants has received much attention because of the emergence of drug-resistant pathogenic bacteria to the existing drugs ${ }^{3}$. Again the search for natural antioxidants has received much attention which can help to prevent oxidative damage occurring in the body ${ }^{4}$. It is known that onset and progression of many chronic and degenerative diseases are caused by disparate physiological, pathological, environmental and lifestyle factors ${ }^{5}$.

In these days, the concept of multi-target drugs or multicomponent therapy is gaining increased attention with the discovery that many diseases like hypertension are best treated by multi-drug or multi-target therapies ${ }^{6}$. Thus, natural antioxidants are gaining popularity among consumers and scientific community because

Author for correspondences: Meena Rajbhandari, Research Centre for Applied Science and Technology, RECAST, TU. Email: karmacharyameena@gmail.com

Received: 9 Aug 2020; First Review: 14 Aug 2020; Second Review: 7 Sep 2020; Third Review: 7 Nov 2020; Accepted: 13 Nov 2020. Doi: https://doi.org/10.3126/sw.v14i14.35000 
epidemiological studies have indicated that their frequent consumption is associated with a lower risk of cardiovascular disease and cancer ${ }^{7}$. It is well known that many valuable drugs derived from plants were discovered through their application in traditional medicine. The acceptability, convenience and accessibility of traditional medicine make them important resources for the discovery of bioactive molecules with therapeutic effects. However, plants synthesize diversity of phytochemical which results in the diversity in their biological activities and drug like properties $^{8}$.

Drymaria diandra, (Synonyme: D. cordata) commonly known as Chickweed and locally known as ‘Abijalo'belongs to Caryophyllaceae family, is a creeping herb grows in dense patches in moist and shady places throughout Nepal to about $2000 \mathrm{~m}$. The plant has been traditionally used to treat diverse ailments. The juice of the root is inhaled to treat sinusitis, the juice of the plant is useful to treat gastric, ulcer, fever, indigestion and conjunctivitis. The plant has laxative and cooling effect, the aerial parts are eaten as a vegetable and paste of the plant is useful for peptic ulcer, fever, cough, cold and headaches ${ }^{9}$. Literature review revealed that many bioactive constituents have been isolated from $D$. diandra. A novel flavonoid glycoside ${ }^{10}$, cyclic peptides ${ }^{11}$, drymaritin, a new anti- HIV alkaloid and diandraflavone, a new C- glycoside flavonoid $^{12}$, new flavone glycosides ${ }^{13}$ have been isolated. In our previous investigation, $D$. diandra did not show wound healing activities ${ }^{14}$.Quantification of phenolics, flavonoids, antioxidant and antimicrobial activity of methanol extract have been carried out ${ }^{15,16}$. In contrast, scientific investigation has not been made on different extracts like hexane, dichloromethane, ethyl acetate, methanol and 50\% aqueous methanol. Thus, the present study was carried out to determine the antimicrobial activity of all the five extracts, total phenolic, flavonoid and sugar content in polar extracts, their antioxidant activity and metabolite profiling of hexane extract by GCMS technique to detect the presence of various bioactive compounds.

\section{MATERIALS AND METHOD}

\section{Plant Materials}

The plant material was collected from Bhaktapur district in February 2016 and authenticated by comparing with the voucher specimens deposited at Central Department of Botany Tribhuvan University, Kathmandu, Nepal. The voucher specimen (DD-16-SK) was deposited at Research Centre for Applied Science and Technology, RECAST, Tribhuvan University.

\section{General experimental procedure}

DPPH and authentic $( \pm)$ - catechin were purchased from Sigma Chemical Company, USA. Gallic acid was purchased from Merck, Darmstadt, Germany. Aluminium chloride (SD fine-chemicals), Folin- Ciocalteu (SD finechemicals) and anthrone (Thomas baker) were purchased from a local vendor. All other chemicals and solvents were of analytical grade and purchased from local vendors. Absorbance was measured using Chemito UV- VIS Spectrophotometer. Analytical GC-MS was carried out on JEOL AccuTOF GCX Time of Flight Mass-spectrometer fitted with Agilent 7693A type GC injector and a HP5 capillary column.

\section{Extraction}

The dried and powdered aerial parts of D. diandra $(100 \mathrm{~g})$ were extracted successively with hexane $(250 \mathrm{ml}, 6$ times, $18 \mathrm{~h}$ ), dichloromethane ( $300 \mathrm{ml}, 6$ times, $18 \mathrm{~h})$, ethyl acetate $(200 \mathrm{ml}, 4$ times, $18 \mathrm{~h})$ and methanol $(200 \mathrm{ml}, 5$ times, $18 \mathrm{~h}$ ) by cold percolation. The residue after extraction with methanol was refluxed with $50 \%$ aqueous methanol (400 $\mathrm{ml}, 4 \mathrm{~h})$. The extracts were filtered separately and the solvent was evaporated under reduced pressure in a Rotavapor to get respective crude extracts. The dried extracts were stored at $-20{ }^{\circ} \mathrm{C}$ for further use.

\section{Phytochemical screening}

The freshly prepared crude extracts were tested for the presence of various classes of phytochemical using standard procedures ${ }^{17}$. 


\section{Determination of total phenolic content}

Total phenolic content in plant extracts was determined by using Folin-Ciocalteucolouri metric method based on oxidation-reduction reaction ${ }^{18}$. Total phenolic content of the extracts was expressed as mg gallic acid equivalents (GAE) per gram dry extract (mg/g).

\section{Determination of total flavonoid content}

Total flavonoid content was determined by aluminum chloride colorimetric assay ${ }^{19}$. Total flavonoid content of the extracts was expressed as $\mathrm{mg}$ catechin equivalents (CE) per gram of dry extract $(\mathrm{mg} / \mathrm{g})$.

\section{Determination of total sugar content}

Total sugar content in plant extracts was estimated by using anthrone reagents based colorimetric method ${ }^{20}$. Total sugar content of the extracts was expressed as mg glucose equivalents $(\mathrm{GE})$ per gram of dry extract $(\mathrm{mg} / \mathrm{g})$.

\section{Calculation}

The total phenolic, flavonoid, and sugar content were calculated in all the extracts separately using the formula, $\mathrm{C}=\mathrm{cV} / \mathrm{mwhere}, \mathrm{C}$, Total content of phenol/flavonoid/sugar compounds in $\mathrm{mg} / \mathrm{g}$, c, concentration of gallic acid $/( \pm)$ catechin/D-glucose established from the calibration curve in $\mathrm{mg} / \mathrm{mL}, \mathrm{V}$, volume of extract in $\mathrm{mL}, \mathrm{m}$, weight of plant extract. Data were recorded as a mean $( \pm)$ standard deviation of three determinations of absorbance for each concentration, from which linear correlation coefficient $\left(\mathrm{R}^{2}\right)$ value was calculated using MS Office Excel 2007. The linear regression equation for a straight line is, $[\mathrm{y}=\mathrm{mx}+\mathrm{c}]$ where, $y$, absorbance of extract, $\mathrm{m}$, slope of the calibration curve, $\mathrm{x}$, concentration of extract, $\mathrm{c}$, intercept. Using this regression equation, concentrations of extracts were calculated. From the calculated values of concentration of each extract, the total phenolics, flavonoid and sugar content were calculated.

\section{Determination of antioxidant activity using DPPH free} radical

Antioxidant activity of the selected extracts was assessed using DPPH free radical $^{21}$.

\section{Determination of antibacterial activity}

One Gram positive bacteria, S. aureus (ATCC 25923) and one Gram negative bacteria, E. coli (ATCC 25922) were used to determine the antibacterial activity of the extracts. Agar well diffusion method was usedto determine the antimicrobial activity ${ }^{21}$.

\section{GC-MS analysis of hexane extract}

Analytical GC-MS of hexane extract was carried out on JEOL Accu TOF GCX Time of Flight Mass-spectrometer fitted with Agilent 7693A type GC injector and a HP5 capillary column (29.2 m x $0.25 \mathrm{~mm}$ i.d., film thickness 0.25 $\mu \mathrm{m})$. The initial oven temperature was maintained at $80^{\circ} \mathrm{C}$ withhold time of 1 minute. The temperature was gradually increased to $320{ }^{\circ} \mathrm{C}$ at a rate of $15{ }^{\circ} \mathrm{C} /$ minute. The maximum oven temperature was maintained at $325^{\circ} \mathrm{C}$ and kept at final temperature for 5 minutes. The ion chamber temperature was maintained to $250{ }^{\circ} \mathrm{C}$ while GC interface temperature and inlet temperature was maintained to 300 ${ }^{\circ} \mathrm{C}$. Diluted sample $(0.5 \mu \mathrm{L})$ was injected in the splitless mode. Helium was used as a carrier gas with a flow rate of $1.2 \mathrm{~mL} / \mathrm{min}$. MS was operated in electron impact mode with ionization energy of $70 \mathrm{eV}$. Full scan mass spectra were acquired from 25-600 amu. The total run time was 22 minutes. The detected compounds were identified by processing the raw GC-MS data with msAxel software (Version 1.1.6.17127 Copyright 2014-2015JEOL Ltd.) and comparing with NIST mass spectral library (Mass spectral Program for the National Institute of Standards and Technology/Environment Protection Agency/National Institute of Health Mass Spectral Library, Version 2.2).

\section{RESULTS AND DISCUSSION}

The aerial parts of dried and crushed D. diandra (100 g) was successively extracted with hexane, dichloromethane, ethylacetate and methanol by percolation. The residue was refluxed with $50 \%$ aqueous methanol to get the respective extracts. The highest amount of extract was obtained with methanol and the lowest amount was obtained with $50 \%$ methanol. The results of the yield of the extracts are shown in Table 1. The results of the phytochemical screening of different extracts revealed that only terpenoids and quinones are present in the hexane, dichloromethane andethyl acetate extracts. Phenolics, flavonoids, tannins, glycosides and reducing sugars are present in the 
methanoland $50 \%$ aqueous methanol extracts. The results are shown in Table 1.

Table 1. Yield and phytochemical screening of different extracts

\begin{tabular}{|c|c|c|c|c|c|}
\hline Extracts & $\begin{array}{l}\text { Hexan } \\
\text { e }\end{array}$ & $\mathrm{CH}_{2} \mathrm{Cl}_{2}$ & $\begin{array}{l}\text { EtOA } \\
c\end{array}$ & $\begin{array}{l}\mathrm{MeO} \\
\mathrm{H}\end{array}$ & $\begin{array}{l}50 \% \\
\mathrm{MeOH}\end{array}$ \\
\hline Yield in $g$ & 2.66 & 3.22 & 2.09 & 5.04 & 1.54 \\
\hline Phenolics & - & - & - & + & + \\
\hline Flavonoids & - & - & - & + & + \\
\hline Alkaloids & - & - & - & - & - \\
\hline $\begin{array}{l}\text { Terpenoid } \\
\mathrm{s}\end{array}$ & + & + & + & - & - \\
\hline Glycosides & - & - & - & + & + \\
\hline Tannins & - & - & - & + & + \\
\hline R. sugars & - & - & - & + & + \\
\hline Quinones & + & + & + & - & - \\
\hline
\end{tabular}

$(+)$ indicates present and (-) indicates absent

\section{Total phenolic content}

Plant derived polyphenols including flavonoids and tannins possess several biological properties and thusnecessitate evaluating their presence in different extracts prepared in different organic solvents. A simple andreproducible FolinCiocalteu (FC) method was applied for the determination of total phenolic content using gallic acid as a standard although there is possible interference from other readily oxidizable compounds present in plant extracts. The absorbance values obtained at different concentrations of gallic acid was used for the construction of calibration curve. FC method is based on the transfer of electrons in alkaline medium from phenolic compounds to phosphomolybedic/phosphotungstic acid complexes to form blue colored complexes, $\left(\mathrm{PMoW}^{11} \mathrm{O}_{40}\right)^{-4}$, that are determined spectrophotometrically at $760 \mathrm{~nm}$. The total phenolic content in different extracts were calculated from the calibration curve using regression equation $\mathrm{Y}=0.013 \mathrm{x}$, $\mathrm{R}^{2}=0.999$ followed by the formula $\mathrm{C}=\mathrm{cV} / \mathrm{m}$ and expressed as $\mathrm{mg}$ gallic acid equivalent (GAE) per $\mathrm{g}$ of extract in dry weight $(\mathrm{mg} / \mathrm{g})$. The results indicated that the total phenolic content in the methanol extracts (190.58 $\pm 0.2 .21 \mathrm{mg} \mathrm{GAE} / \mathrm{g}$ extract) was found to be higher than in the $50 \%$ aqueous methanol extract $(82.42 \pm 8.41 \mathrm{mg}$
GAE/g extract). The total phenolic content in our sample is relatively high in comparison to the literature data $(122.45 \pm 0.96 \mathrm{GAE} / \mathrm{g})^{15}$. This may be due to the difference in extraction method as well as the season of collection and collection site of the plant materials. The results are shown in Table 2. Further, the highest yield and total phenolic content obtained in the methanol extract of could be attributed to its high polarity. Another possible reason might be due to the establishment of complexes by phenolic constituents with other biomolecules such as proteins, carbohydrates $^{22}$.

\section{Total flavonoid content}

The total flavonoid content in different extracts was estimated by aluminium chloride colorimetric assay using $( \pm)$-catechin as a standard. The absorbance values obtained at different concentrations of catechin was used for the construction of calibration curve. The principle involved in aluminium chloride colorimetric method is that it forms acid stable complexes with the either keto groups and/or group of flavones and flavonols. In addition it also forms acid labile complexes with the ortho-dihydroxyl groups of the flavonoids which give pink colour in alkaline medium whose absorbance was measured spectrophotometerically. The total flavonoid content in different extracts were calculated from the calibration curve using regression equation $\mathrm{Y}=0.004 \mathrm{x}, \mathrm{R}^{2}=0.991$ followed by the formula $\mathrm{C}=\mathrm{cV} / \mathrm{m}$ and expressed as $\mathrm{mg}( \pm)$-catechin equivalent (CE) per $\mathrm{g}$ of extract in dry weight $(\mathrm{mg} / \mathrm{g})$. The results of this investigation indicated that the total flavonoid content inthe methanol extract $(69.25 \pm 7.91 \mathrm{CE} / \mathrm{g}$ extract) was found to be slightly higher than that of the $50 \%$ aqueous methanol extract $(61.86 \pm 4.91 \mathrm{CE} / \mathrm{g}$ extract). The total flavonoid content in our sample is relatively high in comparison to the literature data $(11.51 \pm 0.30 \quad \mathrm{QE} / \mathrm{g}$ extract $)^{15}$. This could be due to the selection of different standards for the construction of calibration curve. Quercetin was used as a standard in the literature while catechin was used in our investigation. The results are shown in Table 2.

The ratios of total flavonoid to total phenolic content were found to be different in methanol and 50\% aqueous 
methanol extracts. In the case of methanol extract, the ratio ( 0.363$)$ was observed which indicated that $36.3 \%$ of totalphenolics are flavonoids. Similarly in the case of $50 \%$ methanol extract, the ratio $(0.750)$ was observed whichindicated that $75.0 \%$ of total phenolics are flavonoids. The results are shown in Table 2.

\section{Total sugar content}

Plant polysaccharides have significant therapeutic potential and could be the source of novel immunomodulatory medicine. Many immunomodulatory plant polysaccharides have been isolated and characterized from medicinal plants ${ }^{23,24}$. This has initiated to evaluate their presence in different plant extracts. Anthrone reagent based colorimetric assay using D-glucose as a standard was used to determine the total sugar content in plant extracts. Plant extracts containing sugars were first hydrolysed into simple sugars using dilute hydrochloric acid. In hot acidic medium glucose is dehydrated to hydroxymethyl furfural that with anthronale, an enol form of anthrone forms a green coloured product with an absorption maximum at $630 \mathrm{~nm}$ which was measured against blank consisting of anthrone solution and distilled water.The absorbance values obtained at different concentrations of glucose was used for the construction of calibration curve. The total sugar content in different extracts were calculated from the calibration curve using regression equation $\mathrm{Y}=0.013 \mathrm{x}, \mathrm{R}^{2}=0.994$ followed by the formula $\mathrm{C}=\mathrm{cV} / \mathrm{m}$ and expressed as $\mathrm{mg}$ glucoseequivalents (GE) per $\mathrm{g}$ of extract in dry weight $(\mathrm{mg} / \mathrm{g})$. Our finding revealed that the $50 \%$ aqueous methanol extract was found to contain higher amount of carbohydrate (185.60 \pm 2.33 $\mathrm{GE} / \mathrm{g})$ than the methanol extract $(61.48 \pm 3.16 \mathrm{GE} / \mathrm{g})$. The results are shown in Table 2.

\section{Antioxidant activity using DPPH free radical}

The DPPH assay was carried out for methanol and 50\% aqueous methanol extracts. The absorbance values were measured at wavelength $517 \mathrm{~nm}$ for different concentrations of extracts and the control. These values were used to calculate the percentage inhibitions of DPPH radical against the samples. The $\mathrm{IC}_{50}$ values of various extracts were calculated from the percentage inhibitions at various concentrations are given in Table 2. The results showed that the $\mathrm{IC}_{50}$ value of the methanol extract was found to be lower $(13.61 \mu \mathrm{g} / \mathrm{ml})$ than the $\mathrm{IC}_{50}$ value of $50 \%$ aqueous methanol extract $(16.94 \mu \mathrm{g} / \mathrm{ml})$. Our sample showed relatively strong antioxidant activity in comparison to the reported date $\left(\mathrm{IC}_{50} 26.27 \pm 0.19\right)^{15}$. The earlier reports have not compared the effect of different solvents during extraction. The stronger antioxidant activity may be correlated with the presence of higher amounts of phenolics/flavonoids in our sample as evidenced by our phytochemical analysis (Table 2). Antioxidants have the ability to prevent various oxidative. stress related cell damages mediated by free radicals. Many antioxidant molecules are recorded in several medicinal plants and thus will be beneficial in the treatment of several human diseases ${ }^{25}$. In the human body, cell damage may induce the generation of increased levels of free radicals. Various disorders including myocardial infarction, cancer, atherosclerosis and neurogenerative disorders are mainly correlated to these free radicals ${ }^{26}$.

\section{Antibacterial activity}

Plants used in the traditional medicine could be an alternative source of antimicrobial drugs. In this regard, we evaluated the antimicrobial properties of different extracts of D. diandra and the results were very conclusive. The hexane, dichloromethane, ethylacetate, methanol and 50\% aqueous methanol extracts were screened for antimicrobial activity against $S$. aureusand $E$. coli by agar well diffusion method. An aliquot of 5 and 10 mg each extract prepared in DMSO was introduced into each well. Negative control experiment was performed using equivalent volume of DMSO and positive control experiment was performed by the use of a standard antibiotic, amoxicillin disc $(10 \mu \mathrm{g})$. At the end of the incubation period, the clear inhibition zones of bacterial growth around the wells were observed in the presence of 
different extracts. The results are shown in Table 2. The results of antibacterial assay revealed that all the extracts showed activity against both bacteria. Microbial inhibition was found to vary slightly with the type of extracts evaluated. The greater activity was shown by dichloromethane extract with an inhibition zone of $22 \mathrm{~mm}$ against E. coli and $20 \mathrm{~mm}$ against $S$. aureusat a concentration of $10 \mathrm{mg} /$ well. It could be due to more soluble bioactive compounds extracted with dichloromethane such as terpenoids and quinones (Table 1). A lesser activity was shown by $50 \%$ methanol extract with an inhibition zone of $10 \mathrm{~mm}$ against $E$. coli and 11 $\mathrm{mm}$ against $S$. aureus at a concentration of $10 \mathrm{mg} / \mathrm{well}$. It could be due to the presence of mainly phenolics, flavonoids and tannins (Table1). Mostly gram negative bacteria exhibit more resistant properties against a wide range of antibiotics or chemical drugs when compared to gram positive bacteria due to the differences in their cell wall and outer membrane structures ${ }^{27-29}$. However, both gram positive and gram negative bacterial were effectively inhibited by all the extracts. Thus, the extracts of $D$. diandra could be beneficial in treating the diseases caused by $S$. aureus and E. coli. In contrast to our findings, it was reported that the methanol extract of $D$. diandra did not show antibacterial activity against $E$. coli ,Klebsiella sp. And Serratia $s p^{16}$.

Table 2. Antimicrobial activity, total phenolic, total flavonoid, total sugar and DPPH free radical scavenging activity.

\begin{tabular}{|c|c|c|c|c|c|c|c|c|c|}
\hline \multirow[b]{2}{*}{$\begin{array}{l}\text { Plant } \\
\text { extracts }\end{array}$} & \multirow[b]{2}{*}{ Bacteria } & \multicolumn{3}{|c|}{ Inhibition zone $(\mathrm{mm})$} & \multirow[b]{2}{*}{$\begin{array}{c}\text { TPC } \\
\mathrm{mg} \mathrm{GAE} / \mathrm{g}\end{array}$} & \multirow[b]{2}{*}{$\begin{array}{c}\mathrm{TFC} \\
\mathrm{mg} \mathrm{CE} / \mathrm{g}\end{array}$} & \multirow{2}{*}{$\begin{array}{l}\text { Ratio } \\
\text { TF/TP }\end{array}$} & \multirow[b]{2}{*}{$\begin{array}{c}\mathrm{TSC} \\
\mathrm{mg} \mathrm{GE} / \mathrm{g}\end{array}$} & \multirow[b]{2}{*}{$\begin{array}{c}\text { DPPH } \\
\mathrm{IC}_{50} \\
(\mu \mathrm{g} / \mathrm{ml})\end{array}$} \\
\hline & & $\begin{array}{c}5 \\
\mathrm{mg} / \mathrm{we} \\
1 \mathrm{l}\end{array}$ & $\begin{array}{c}10 \\
\mathrm{mg} / \text { well }\end{array}$ & $\begin{array}{c}\text { Contro } \\
1\end{array}$ & & & & & \\
\hline \multirow{2}{*}{ Hexane } & E. coli & 15 & 15 & - & \multirow{2}{*}{-} & \multirow{2}{*}{ - } & \multirow{2}{*}{ - } & \multirow{2}{*}{-} & \multirow{2}{*}{ - } \\
\hline & S. aureus & 12 & 12 & - & & & & & \\
\hline \multirow{2}{*}{ DCM } & E. coli & 17 & 22 & - & \multirow{2}{*}{ - } & \multirow{2}{*}{ - } & \multirow{2}{*}{-} & \multirow{2}{*}{ - } & \multirow{2}{*}{ - } \\
\hline & S. aureus & 18 & 20 & - & & & & & \\
\hline \multirow{2}{*}{ EtOAc } & E. coli & 16 & 17 & - & \multirow{2}{*}{ - } & \multirow{2}{*}{ - } & \multirow{2}{*}{ - } & \multirow{2}{*}{ - } & \multirow{2}{*}{ - } \\
\hline & S. aureus & 12 & 15 & - & & & & & \\
\hline \multirow{2}{*}{$\mathrm{MeOH}$} & E. coli & 15 & 15 & - & \multirow{2}{*}{$190.58 \pm 2.21$} & \multirow{2}{*}{$69.25 \pm 7.91$} & \multirow{2}{*}{0.363} & \multirow{2}{*}{$61.48 \pm 3.16$} & \multirow{2}{*}{13.61} \\
\hline & S. aureus & 12 & 13 & - & & & & & \\
\hline \multirow{2}{*}{$\begin{array}{c}50 \% \\
\mathrm{MeOH}\end{array}$} & E. coli & 10 & 10 & - & \multirow{2}{*}{$82.42 \pm 8.41$} & \multirow{2}{*}{$61.86 \pm 4.91$} & \multirow{2}{*}{0.750} & \multirow{2}{*}{$185.60 \pm 2.53$} & 1604 \\
\hline & S. aureus & 11 & 11 & - & & & & & 10.94 \\
\hline Amoxic & E. coli & - & - & 22 & & & & & \\
\hline illin & S. aureus & - & - & 36 & 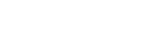 & 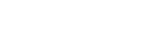 & 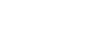 & 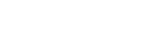 & 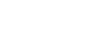 \\
\hline
\end{tabular}

Note: Inhibition zone was measured including well and disc

\section{GC-MS of hexane extract}

The chemical composition of hexane extract of $D$. diandrawas determined by GC-MS technique. The chromatogram is shown in Fig 1. The GC-MS analysis of the hexane extract revealed the presence of more than 22 compounds. However, 9 compounds were identified on the basis of the fragmentation pattern of each compound in mass spectrum and comparison with the standard NIST mass spectral database. The identified compounds were one diterpene, one phthalate ester, two hydrocarbons and four saturated aldehydes. The results are shown in Table 3. The Gas chromatogram is shown in Fig 1. The mass spectrum of one of the compound eluted at $9.861 \mathrm{~min}$ and its comparison with the mass spectrum of neophytadieneavailable in NIST library is shown Fig 2. 


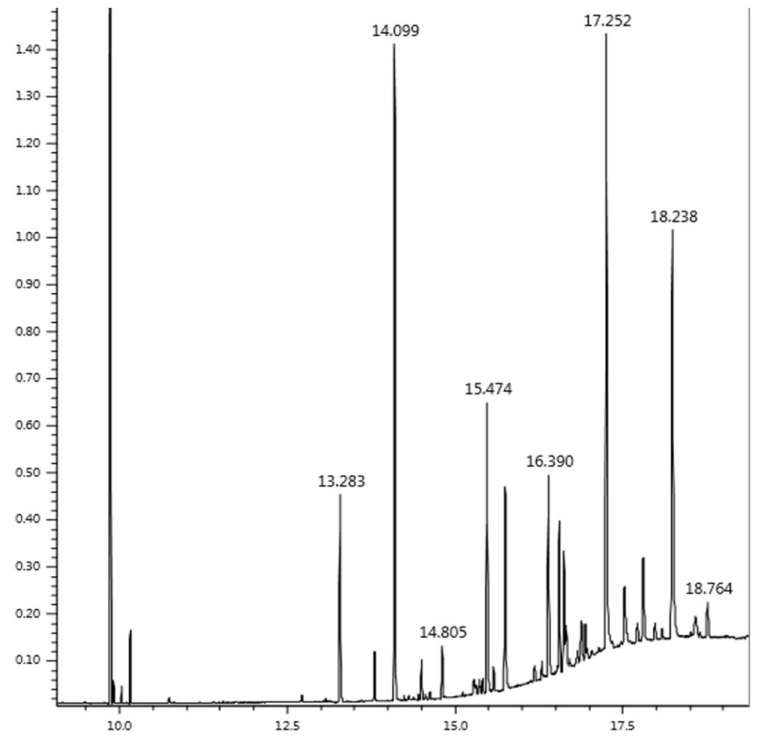

Figure 1: Gas chromatogram of hexane extract.

Figure 2: Mass spectrum of the compound eluted at $9.861 \mathrm{~min}$ (above) and the mass spectrum of neophytadiene available in NIST library (below).

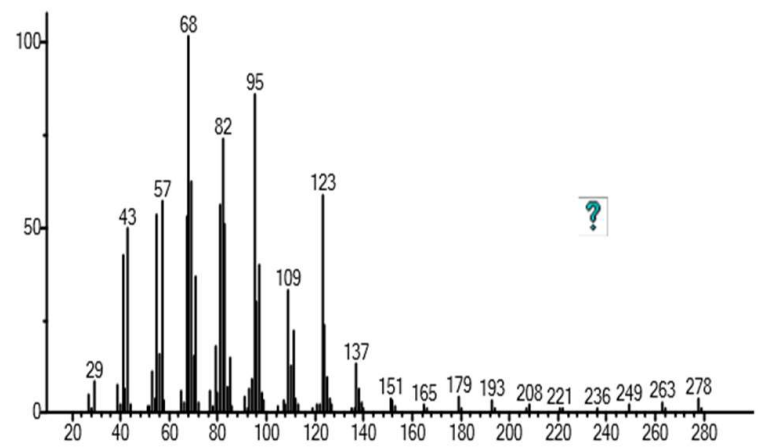
(Text Fle) Subtract [MS: 9.8540-9.8673. MS: 10.2868-10.4866]/ juer112159-Centroid/ heil/ Juli_16

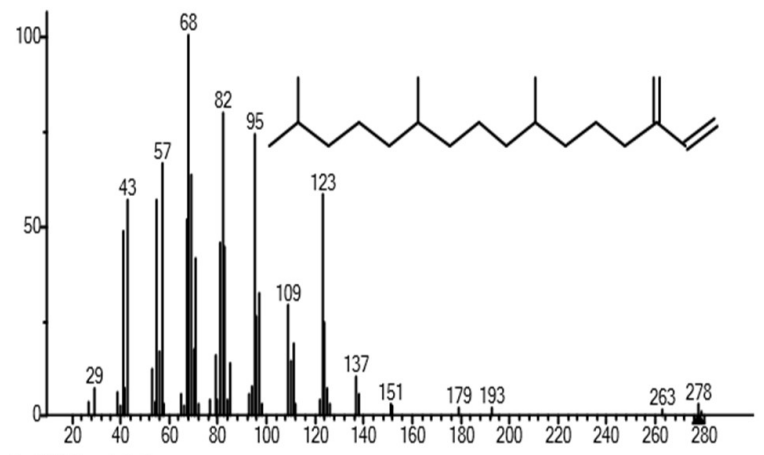

Plants synthesize various chemicals to protect them against predators and microbial attacks. They differ from plant to the plant families. Neophytadiene, which is present in several plants and the green alga showed strongantibacterial activity ${ }^{30}$. Several aliphatic saturated and unsaturated aldehydes are produced by enzymatic cleavage of fatty acids when plants are attacked by microbes $^{31}$. The long-chain aldehydes from olive oil have shown antibacterial activity against both gram-positive and gram-negative microorganisms that caused human intestinal and respiratory tract infections ${ }^{32}$.The antibacterial activity of the hexane extract could be due to the presence of neophytadiene together with aldehydes like triacontanal and henicosanal and other compounds. Their synergistic/addative effect could be more pronounced than that of the individual component.

Table 3. Results of GC-MS of hexane extract.

\begin{tabular}{|l|l|l|}
\hline Name of compounds & Chemical class & $\begin{array}{l}\text { Retention } \\
\text { time }\end{array}$ \\
\hline Neophytadiene & Diterpene & 9.861 \\
\hline Di-isooctyl phthalate & Phthalate ester & 14.009 \\
\hline Tetracosanal & $\begin{array}{l}\text { Saturated } \\
\text { aldehyde }\end{array}$ & 15.474 \\
\hline Hentriacontane & Hydrocarbon & 15.745 \\
\hline Octacosanal & $\begin{array}{l}\text { Saturated } \\
\text { aldehyde }\end{array}$ & 16.390 \\
\hline $\begin{array}{l}\text { Stigmastan-3,5,22- } \\
\text { trien }\end{array}$ & \begin{tabular}{l} 
Sterol \\
\hline 2-Methylhexacosane
\end{tabular} & $\begin{array}{l}\text { Hydrocarbon } \\
\text { Triacontanal }\end{array}$ \\
\hline Henicosanal & $\begin{array}{l}\text { Saturated } \\
\text { aldehyde }\end{array}$ & 16.624 \\
\hline
\end{tabular}

\section{CONCLUSION}

The present research highlighted the phenolic, flavonoid, sugar content of different extracts, their antioxidant, antibacterial activity and GC-MS profiling of hexane extract of $D$. diandra. The polar extracts are the good 
source of phenolics, flavonoids and carbohydrates with high antioxidant activity. Non polar and medium polar extracts are the source of antibacterial compounds. When comparing our results with the reported results, our plant looked different in terms of phytochemical contents and biological activity. Thus, this plant can serve as a new natural source for obtaining many therapeutically valued metabolites against various diseases. The results are in agreement with the traditional belief for which they use as medicine for the treatment of various ailment.

\section{ACKNOWLEDGEMENTS}

The authors are grateful to Dr. Guido Jurgenliemk, University of Regensburg, Germany for providing GC-MS spectra and University Grants Commission, Bhaktapur for faculty research grant.

\section{REFERENCES}

1. Nostro, A., Germano, M.P., Dangelo, V., Marino, A., and Cannatelli, M.A. 2000. Extraction methods and bioautography for evaluation of medicinal plant antimicrobial activity. Letter of Applied Microbiology. 30: 379-384.

2. Farnsworth, N.R., Akerele, O., Bingel, A.S., Soejarto, D. D., Guo, Z. 1985. Medicinal Plants in Therapy. Bulletin of WHO. 63: 965981.

3. Cragg, G.M., Newman, D.J. and Snader, K. M. 1997. Natural products in drug discovery and development. Journal of Natural Products. 60: 52-60.

4. Halliwell, B. 1999. Antioxidant defence mechanisms: from the beginning to the end (of the beginning). Free Radical Research. 31: 261-72.

5. Willett, W. C. 2002. Balancing life-style and genomics research for disease prevention. Science. 296: 695-698.

6. Wang, Y., Fan, X., Qu, H., Gao, X. and Cheng, Y. 2012. Strategies and techniques for multi-component drug design from medicinal herbs and traditional Chinese medicine. Current Topics in Medicinal Chemistry. 12: 1356-1362.

7. Temple, N.J. 2000. Antioxidant \& Diseases: More questions than answers. Nutrition Research. 20: 499-495.

8. Yuan, H. Ma, Q., Ye, L. and Piao, G. 2016. The Traditional Medicine and Modern Medicine from Natural Products. Molecules. 21: 559-576.

9. Manaandhar, N. P. 2002. Plants and people of Nepal. Timber Press, Portland, Oregon, USA.
10. Ding, Z.T., Zhou, J., and Tan, N.H. 1999. A novel flavonoid glycoside from Drymaria diandra.PlantaMedica.. 65: 578-579.

11. Ding, Z.T., Zhou, J., Tan, N. H., and Teng, R.W. 2000. Two new cyclic peptides from Drymariadiandra. PlantaMedica. 66:386-388.

12. Hsieh P.W., Chang F.R., Lee K.H., Hwang T.L., Chang S.M. and Wu Y.C. 2004. A new anti- HIV alkaloid: Drymaritin and a new C- glycoside flavonoid, diandraflavone from Drymariadiandra. Journal of Natural Products. 67:1175- 1177.

13. Ding, Z.T., Yang, X.Q., Cao, Q.E. 2005. Three New Flavone Glycosides from Drymariadiandra.Journal of Integrative Plant Biology.47: 1140-1144.

14. Zimmermann-Klemd, A.M, Konradi, V., Steinborn, C., Uecker, A., Falanga, C.M., Woelfle, U., Huber, R., Juergenliemk, G., Rajbhandari, M., and Gruendemann, C. 2019. Influence of traditionally used Nepalese plants on wound healing and immunological properties using primary human cells in vitro. Journal of Ethnopharmacology.235: 415- 423.

15. Sharma, K.R, Kalauni, S.K., Awale, S., and Pokharel, Y.R. 2015. In Vitro Free Radical Scavenging Activity of Methanol Extracts of Some Selected Medicinal Plants of Nepal. Austin Journal of Biotechnology and Bioengineering. 2: 1035-1039.

16. Adhikary, P., K.C., R., Kayastha, D., Thapa, D., Shrestha, R., Shrestha, T.M. and Gyawali, R. 2011. Phytochemical Screening and Anti-Microbial Properties of Medicinal Plants of Dhunkharka Community, Kavrepalanchowk, Nepal. International Journal of Pharmaceutical \& Biological Archives. 2:1663-1667.

17. Culie, I. 1982. Methology for analysis of vegetable drugs, Practical manuals on industrial utilization of medicinal and aromatic plant. Phytochemistry. 63: 97-104.

18. Bhandari, L and Rajbhandari, M. 2014. Isolation of Quercetin from Flower Petals, Estimation of Total Phenolic, Total Flavonoid and Antioxidant Activity of the Different Parts of Rhododendron Arboreum Smith. Scientific World. 12: 34-40.

19. Acharya, P.P., Genwali, G.R. and Rajbhandari, M. 2013. Isolation of Catechin from Acacia CatechuWilldenow Estimation of Total Flavonoid Content in Camellia SinensisKuntze And Camellia SinensisKuntze Var. Assamica Collected from Different Geographical Region and their Antioxidant Activities. Scientific World. 11: 32-36.

20. Poudel, M. and Rajbhandari, M. 2020. Phytochemical Analysis of AmpelopterisProlifera (Retzius) Copeland. Nepal Journal of Science and Technology. 19: 78-88.

21. Paneru, D.P. and Rajbhandari, M. 2020. Phytochemical Analysis and Antimicrobial Activity of Smilax ovalifoliaRoxb. Ex D. Don. Nepal Journal of Science and Technology. 19: 89-96.

22. Esmaeili, A. K., Taha, R.M., Mohajer, S. and Banisalam, S. 2015. Antioxidant activity and total phenolic and flavonoid content of various solvent extracts from in vivo and in vitro grownTri-folium pratense L.(Red Clover). BioMed Research International. doi.org/10.1155/2015/643285. 
23. Kralovec, J.A., Metera, K.L., Kumar, J.R., Watson, L.V., Girouard, G.S., Guan, Y., Carr, R.I., Barrow, C.J. and Ewart, H.S. 2007. Immunostimulatory principles from Chlorella pyrenoidosa-part 1: isolation and biological assessment in vitro. Phytomedicine. 14: 5767.

24. Sun, W., Meng, K., Qi, C., Yang, X., Wang, Y., Fan, W., Yan, Z., Zhao, X. and Liu, J.2015. Immune-enhancing activity of polysaccharides isolated from Atractylodismacrocephalae Koidz. Carbohydrate Polymers. 126: 91-96.

25. Gonbad, R.A., Afzan, A., Karimi, E., Sinniah, U.R., and Swamy, M.K. 2015. Phytoconstituents and antioxidant properties among commercial tea (Camellia sinensis L.) clones of Iran. Electronic Journal of Biotechnology. 18: 433-438.

26. Swamy, M.K., Sinniah, U. R., and Akhtar, M. S. 2015. In vitro pharmacological activities and GC-MS analysis of different solvent extracts of Lantana camaraleaves collected from tropical region of Malaysia. Evidence-Based Complementary and Alternative Medicine. doi.org/10.1155/2015/506413.

27. Bhatt, P. and Negi, P.S. 2012. Antioxidant and Antibacterial Activities in the Leaf Extracts of Indian Borage (Plectranthusamboinicus). Food and Nutrition Sciences. 03: 146152.

28. Pokharen, N., Dahal, S., and Anuradha, M. 2011. Phytochemical and antimicrobial studies of leaf extract of Euphorbia neriifolia. Journal of Medicinal Plants Research.5: 5785- 5788.

29. Silhavy, T., J., Kahne, D. and S. Walker, S. 2010. The bacterial cell envelope. Cold Spring Harbor Perspectives in Biology. doi: 10.1101/cshperspect.a000414.

30. Mendiola, J.A., Santoyo, S., Cifuentes, A., Reglero, G., Ibáñez, E. and Señoráns, F.J. 2008. Antimicrobial activity of sub- and supercritical $\mathrm{CO}_{2}$ extracts of the green algaDunaliellasalina. Journal of Food Protection. 71: 2138-2143.

31. Kubo, I., Matsumoto, A. and Takase, I. 1985. A multichemical defense mechanism of bitter olive Oleaeuropaea (Oleaceae). Is oleuropein a phytoalexin precursor? Journal of Chemical Ecology. 11: 251-263.

32. Bisignano, G., Lagana, M.G., Trombetta, D., Arena, S., Nostro, A., Uccella, N., Mazzanti, G., Saija, A. 2001. In vitro antibacterial activity of some aliphatic aldehydes from Oleaeuropaea L. FEMS Microbiology Letters. 198: 9-1 